\title{
Investigation on precision and performance for hot gas forming of thin-walled components of $\mathrm{Ti}_{2} \mathrm{AINb}$-based alloy
}

\author{
Xueyan Jiao ${ }^{1,2}$, Zhiqiang Liu ${ }^{1,2}$, Yong $\mathrm{Wu}^{3}$, and Gang $\mathrm{Liu}^{1,2 *}$ \\ ${ }^{1}$ State Key Laboratory of Advanced Welding and Joining, Harbin Institute of Technology, Harbin, 150001, China \\ ${ }^{2}$ School of Materials Science and Engineering, Harbin Institute of Technology, Harbin, 150001, China \\ ${ }^{3}$ College of Mechanical and Electrical Engineering, Nanjing University of Aeronautics and Astronautics, Nanjing, 210016, China
}

\begin{abstract}
Ti}_{2} \mathrm{AlNb}$-based alloys have received considerable attention as potential materials to replace the nickel alloy at $600-750{ }^{\circ} \mathrm{C}$, depending on their advantages of high specific strength, good corrosion and oxidation resistance. To realize the precision and performance control for $\mathrm{Ti}_{2} \mathrm{AlNb}$-based alloy thin-walled components, the microstructure evolution was analyzed for setting up the unified viscoplastic constitutive equations based on the physical variables and simulating the forming process coupled between the deformation and the microstructure evolution. Through the finite element model with coupling of microstructure and mechanical parameters, the microstructure evolution and shape fabricating can be predicted at the same time, to provide the basis for the process parameters optimization and performance control. With the reasonable process parameters for hot gas forming of $\mathrm{Ti}_{2} \mathrm{AlNb}$ thin-walled components, the forming precision and performance can be controlled effectively.
\end{abstract}

Keywords: hydroforming, performance, precision

\section{Introduction}

With the rapid development of aerospace industry, the speed of aircrafts has been dramatically improved, resulting in higher requirement on heat-resistant and lightweight materials. In this case, the $\mathrm{Ti}_{2} \mathrm{AlNb}$-based alloys, combing high specific strength, good oxidation resistance and sufficient creep resistance at elevated temperatures, have great potential application in aerospace field [1-3]. However, the superior hightemperature performance and the intrinsic brittleness have brought difficulties in the deformation of $\mathrm{Ti}_{2} \mathrm{AlNb}$ based alloys, especially for the complex components with irregular section. Moreover, as multi-phase alloys, the $\mathrm{Ti}_{2} \mathrm{AlNb}$-based alloys have multiple phase transformations and compositions, which can result in abundant microstructure morphologies. Boehlert [4] has pointed out that the mechanical properties of the $\mathrm{Ti}_{2}$ AlNb-based alloys were very sensitive to the microstructures, which was determined by the thermal processing and heat treatment history. To achieve the accurate prediction of deformation behavior and microstructure evolution simultaneously, the unified viscoplastic constitutive equations based on the microstructure evolution mechanism were established in this paper.

Developed on the tube and pipe hydroforming process, hot gas forming is considered as one of novel

* Corresponding author: gliu@hit.edu.cn forming processes to produce complicated shaped components of metal materials at high temperature [5]. Compared with the traditional forming technology, the hot gas forming can obtain higher inner-surface accuracy in the closed components with a complex cross-section. In recent years, hot gas forming has been widely applied to manufacturing parts in various fields, such as automobile, aircraft and aerospace, and ship building industry, due to the increasing demands for lightweight parts [6].

In this paper, the simulations of hot gas forming process for the Ti-22Al-24Nb-0.5Mo quadrate tubes were performed using unified viscoplastic constitutive equations. The corresponding hot gas forming process of Ti-22Al-24Nb-0.5Mo quadrate tubes was also conducted to verify the simulation accuracy. The effect of forming temperature on wall thickness distribution, microstructural evolution and mechanical property was investigated.

\section{Unified viscoplastic constitutive equa- tions for Ti-22Al-24Nb-0.5Mo alloy}

The Ti-22Al-24Nb-0.5Mo alloy was tensile tested at $910 \sim 1040^{\circ} \mathrm{C}$ with strain rates of $0.1 \sim 0.0004 \mathrm{~s}^{-1}$ and the deformed samples with different strains were investigated by electron backscattered diffraction (EBSD) 
to gain the microstructural information of grain size, phase volume fraction, recrystallization, and globularization. During the hot deformation, the microstructure evolves with the increasing strain, in turn, the mechanical behavior will be also affected by the microstructural evolution. When the Ti-22Al-24Nb$0.5 \mathrm{Mo}$ alloy was deformed at $950{ }^{\circ} \mathrm{C}$, the obvious softening phenomenon occurred after the peak stress, which is caused by damage and softening mechanism such as dynamic recovery, dynamic recrystallization and globularization. Besides, the temperature-rise induced by plastic deformation also caused the material softening. The softening phenomenon also occurred in this alloy when it was deformed at temperature above $970{ }^{\circ} \mathrm{C}$ with high strain rate, while the strain hardening phenomenon presented with low strain rate because of grain growth during the deformation. The constitutive equation listed in Eq.(1), which considered the microstructure evolutions, including grain size, recrystallization, phase volume fraction, damage, globularization and temperature rise, was established to predict the microstructure evolution and stress variation under a complicated deformation condition. The specific meaning of variables and calculation of parameters have been reported in reference [7]. The genetic algorithm toolbox in the MATLAB software was used to optimize the material parameters in the constitutive model.

$$
\begin{aligned}
& \dot{\varepsilon}_{p, O}=\left(\frac{\sigma /(1-D)-H-\sigma_{0, O}}{\lambda K_{B 2 / \beta}\left(1-\zeta f_{O} \omega\right)}\right)^{n}(\bar{d})^{-\mu} \\
& \dot{\varepsilon}_{p, B 2 / \beta}=\left(\frac{\sigma /(1-D)-H-\sigma_{0, B 2 / \beta}}{K_{B 2 / \beta}\left(1-\zeta f_{O} \omega\right)}\right)^{n}(\bar{d})^{-\mu} \\
& H=B \bar{\rho}^{0.5} \\
& f_{B 2 / \beta}=1-\psi_{1} \exp \left(\psi_{2}\left(T_{T, B 2 / \beta}-T\right)\right) \\
& f_{O}=\psi_{3} \exp \left(\psi_{4}\left(T_{T, O}-T\right)\right) \\
& f_{\alpha_{2}}=1-f_{O}-f_{B 2 / \beta} \\
& \dot{\varepsilon}_{p}=f_{B 2 / \beta} \dot{\varepsilon}_{B 2 / \beta}+f_{O} \dot{\varepsilon}_{O} \\
& \left\{\dot{S}=\frac{q_{1}\left[x \bar{\rho}-\bar{\rho}_{c}(1-S)\right](1-S)^{q_{2}} \dot{\varepsilon}_{p}^{q_{3}}}{\bar{d}}\right. \\
& \bar{\rho}_{c}=q_{4} \dot{\varepsilon}_{p}^{q_{5}} \\
& \dot{x}=q_{6}(1-x) \bar{\rho} \\
& \dot{\bar{\rho}}=A \dot{\varepsilon}_{p}^{\delta} \cdot\left|\dot{\varepsilon}_{p}\right|-k_{1} \bar{\rho} \dot{\varepsilon}_{p}^{\delta_{1}} \cdot\left|\dot{\varepsilon}_{p}\right|-k_{2} \bar{\rho}^{\delta_{2}}-\left[k_{3} \bar{\rho} /(1-S)\right] \dot{S} \\
& \dot{\bar{d}}=\alpha_{1} \bar{d}^{-\gamma_{1}}+\alpha_{2} \dot{\varepsilon}_{p} \bar{d}^{-\gamma_{2}}-\alpha_{3} \dot{S}^{\gamma_{3}} \bar{d}^{\gamma_{4}} \\
& \dot{\omega}=\chi_{1}(1-\omega)+(1-\omega) \chi_{2} \dot{\varepsilon}_{p}^{\chi_{3}} \\
& \dot{T}=\frac{\eta \sigma}{C_{v} d_{n}}\left|\dot{\varepsilon}_{p}\right|-\lambda^{\prime} \Delta T \\
& \dot{D}=\eta_{1}(1-D) \dot{\varepsilon}_{p}^{d_{1}}+\eta_{2} \dot{\varepsilon}_{p}^{d_{2}} \exp \left(\eta_{3} \varepsilon_{p}\right)-\eta_{4} D \\
& \sigma=E(1-D)\left(1-\zeta f_{O} \omega\right)\left(\varepsilon_{T}-\varepsilon_{p}\right)
\end{aligned}
$$

\section{Numerical simulation for hot gas form -ing of quadrate tube}

The established unified viscoplastic constitutive model based on microstructure internal state variables was embedded in the commercial FEM software Abaqus by the subroutine VUMAT. The hot gas forming of quadrate tube was simulated with the constitutive model coupled of microstructure and mechanical parameters. Microstructure evolution and shape fabricating were predicted by the constitutive model at the same time. The simulation was respectively performed at $950{ }^{\circ} \mathrm{C}$, $970{ }^{\circ} \mathrm{C}$ and $990{ }^{\circ} \mathrm{C}$ with forming pressure of $15 \mathrm{MPa}$. The simulated process for hot gas forming of Ti-22Al24Nb-0.5Mo quadrate tube is shown in Fig. 1.
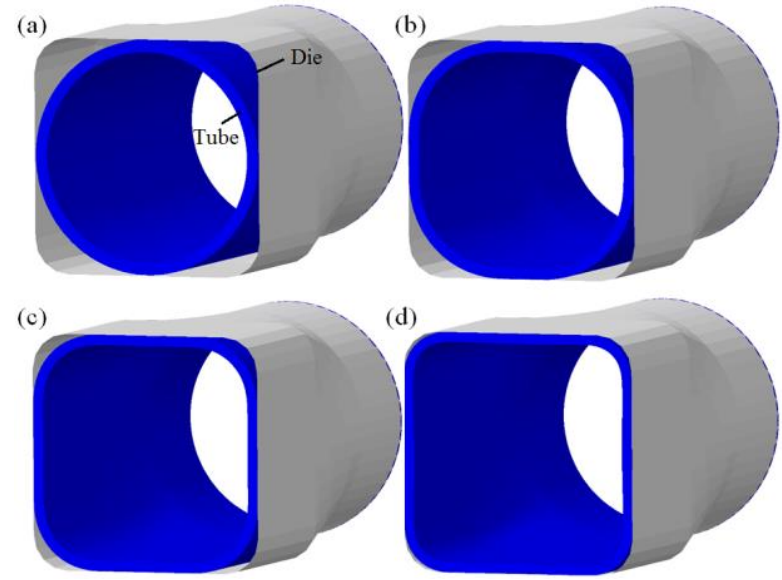

Fig. 1. The simulated process for hot gas forming of Ti-22Al$24 \mathrm{Nb}-0.5 \mathrm{Mo}$ quadrate tube, a) initial status, b-c) intermediate status, d) finished status.

Fig. 2 shows the thickness distribution and the thinning ratio distribution along the quadrate section of tubes. As shown in Fig. 2a, the reducing of wall thickness concentrates on the transition region (TR) between straight region (SR) and round region (RR) due to the effect of friction. As illustrated in Fig. 2b, the severe thinning occurs in the transition region for the tube formed at $950{ }^{\circ} \mathrm{C}$, while the relatively uniform thickness can be achieved in the tube formed at $970{ }^{\circ} \mathrm{C}$ and $990^{\circ} \mathrm{C}$.

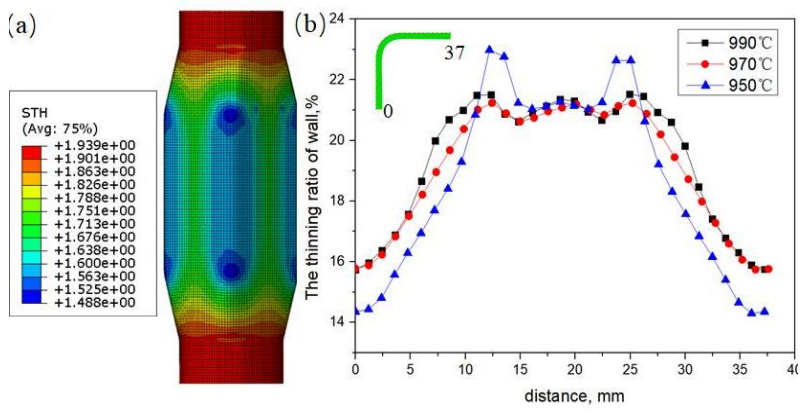

Fig. 2. The simulated results of a) thickness distribution at $\left.970^{\circ} \mathrm{C}, \mathrm{b}\right)$ the thinning ratio distribution along quadrate section of the tubes.

Fig. 3 displays the simulated distributions of strain, stress and microstructural variables for the quadrate tube formed at $970{ }^{\circ} \mathrm{C}$. The strain and stress distributions 
show the analogical trend of that the higher value concentrates on the round region and transition region, as shown in Fig. 3a-b. In accordance with the strain distribution, the distribution of relative dislocation exhibits larger value in the round region and transition region. Besides, the zone with larger strain has smaller relative grain size due to dynamic recovery and dynamic recrystallization, while the undeformed zone shows bigger relative grain size due to the single thermal effect.

Fig. 4 demonstrates the simulated damage distribution for the tubes formed at $950-990{ }^{\circ} \mathrm{C}$. It is found that the severe damage distributes on the round region and transition region, where has performed larger deformation. The damage increases with the increasing strain resulting from the nucleation and growth of defects, such as micro-voids and micro-cracks during deformation. In addition, the damage also increases with the decreasing forming temperature. Since the damage can be partially restored at high temperature, slighter damage is obtained at $990{ }^{\circ} \mathrm{C}$ and $970{ }^{\circ} \mathrm{C}$. As indicated by the simulation results, the distribution of damage and thinning ratio are similar for the tubes formed at $990{ }^{\circ} \mathrm{C}$ and $970{ }^{\circ} \mathrm{C}$, which are much lower than those at $950^{\circ} \mathrm{C}$. Considering the wall thickness, microstructure damage and energy consumption, the forming temperature of $970{ }^{\circ} \mathrm{C}$ is suggested as the optimum deformation temperature.
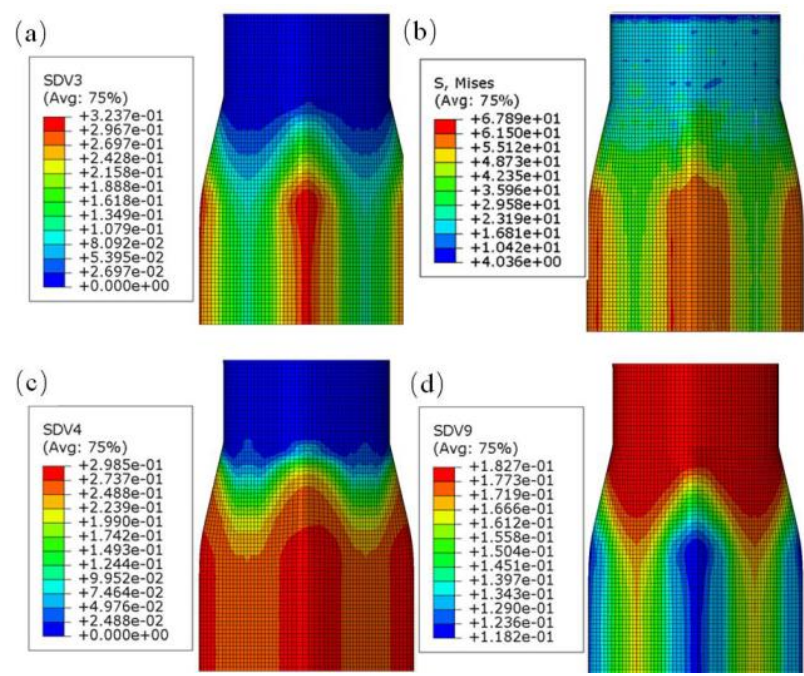

Fig. 3. The simulated distributions of a) strain, b) stress, c) relative dislocation density and d) relative grain size.
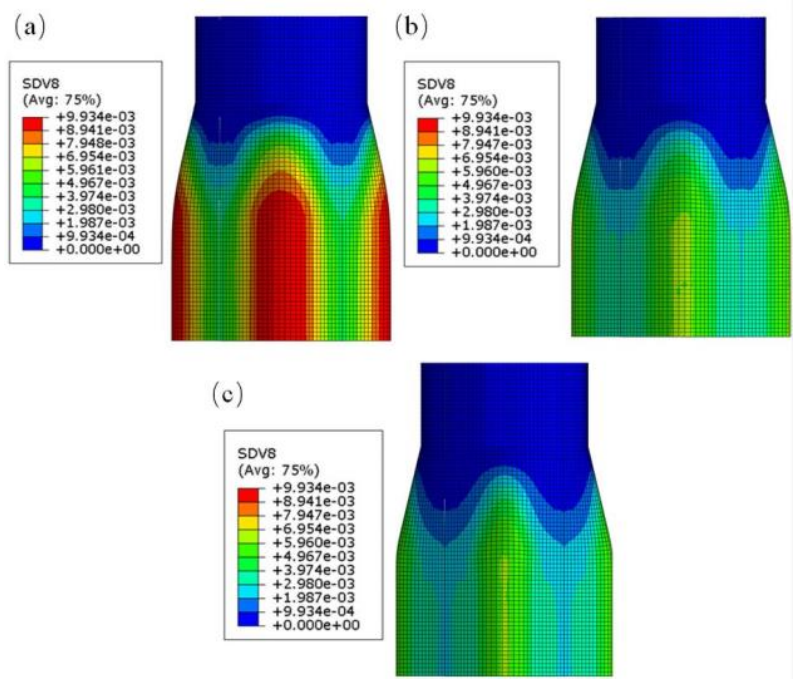

Fig. 4. The simulated results of damage distribution at a) $950{ }^{\circ} \mathrm{C}$, b) $970{ }^{\circ} \mathrm{C}$ and c) $990{ }^{\circ} \mathrm{C}$.

\section{Hot gas forming experiments}

The initial Ti-22Al-24Nb-0.5Mo tube billets with a diameter of $40 \mathrm{~mm}$ and thickness of $2.0 \mathrm{~mm}$ were applied in the experiments. From the microstructure of experimental Ti-22Al-24Nb-0.5Mo alloy shown in Fig. 5, it is noted that the initial microstructure was consisted of equiaxed primary $\alpha_{2}$ phase (dark contrast), lamellar $\mathrm{O}$ phase (gray contrast) and the matrix of $\beta / \mathrm{B} 2$ phase (bright contrast). The hot gas forming process was conducted at $950-990{ }^{\circ} \mathrm{C}$ with forming pressure of 15 $\mathrm{MPa}$ on a self-designed high pressure gas forming platform. The quadrate tube with radius of $6 \mathrm{~mm}$ in round corner was shown in Fig. 6. Tensile specimens with gauge length of $15 \mathrm{~mm}$ and width of $3 \mathrm{~mm}$ were cut from the straight region of the quadrate tubes.

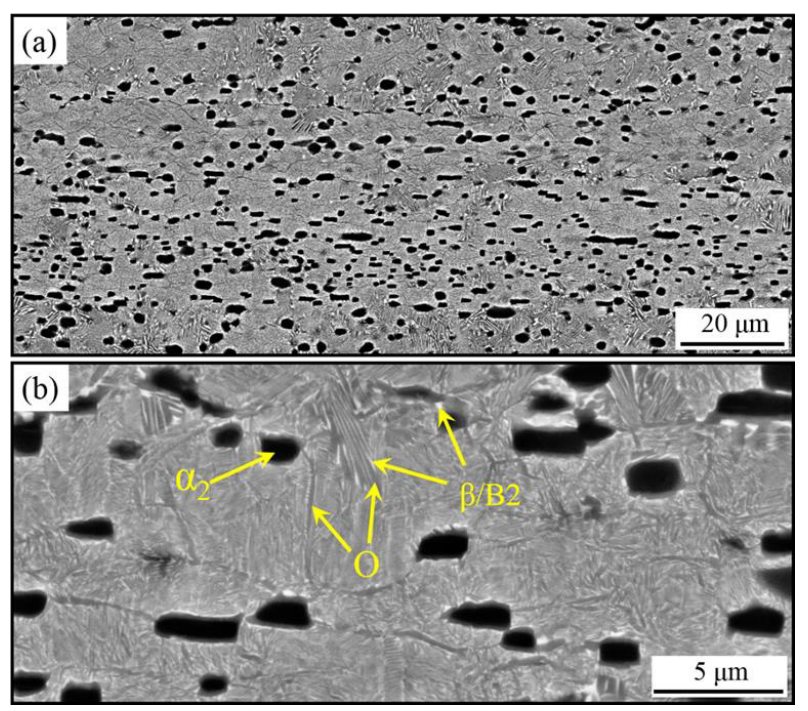

Fig. 5 Microstructure of the experimental Ti-22Al-24Nb$0.5 \mathrm{Mo}$ alloy, a) low magnification image, $\mathrm{b}$ ) high magnification image. 


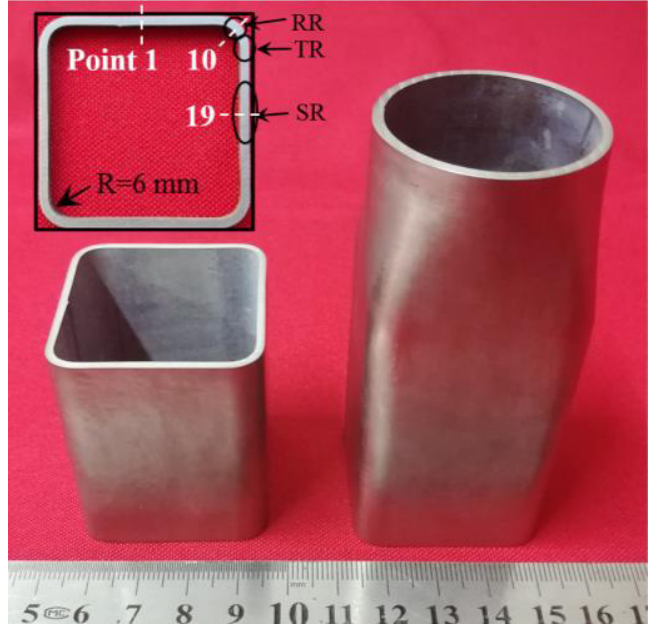

Fig. 6 Hot gas formed quadrate tube.

\section{Mechanical properties and precision of the components}

\subsection{Microstructure and mechanical properties}

Fig. 7 displays the SEM microstructures of the Ti-22Al$24 \mathrm{Nb}-0.5 \mathrm{Mo}$ quadrate tubes formed at different temperatures. Compared to the initial microstructure shown in Fig. 5, the $\mathrm{O}$ phase was significantly coarsened at the forming temperature of $950{ }^{\circ} \mathrm{C}$ and dissolved at and above $970{ }^{\circ} \mathrm{C}$. Furthermore, the volume fraction of coarsened $\mathrm{O}$ phase for the tube formed at $950{ }^{\circ} \mathrm{C}$ was determined to be $19.3 \%$, which would play a key role on the mechanical property. Besides, the matrix $\beta / \mathrm{B} 2$ grains have slightly grown up at $990{ }^{\circ} \mathrm{C}$ due to the partial dissolution of equiaxed $\alpha_{2}$ phase, which contributes to pinning the $\beta / \mathrm{B} 2$ grain boundaries.

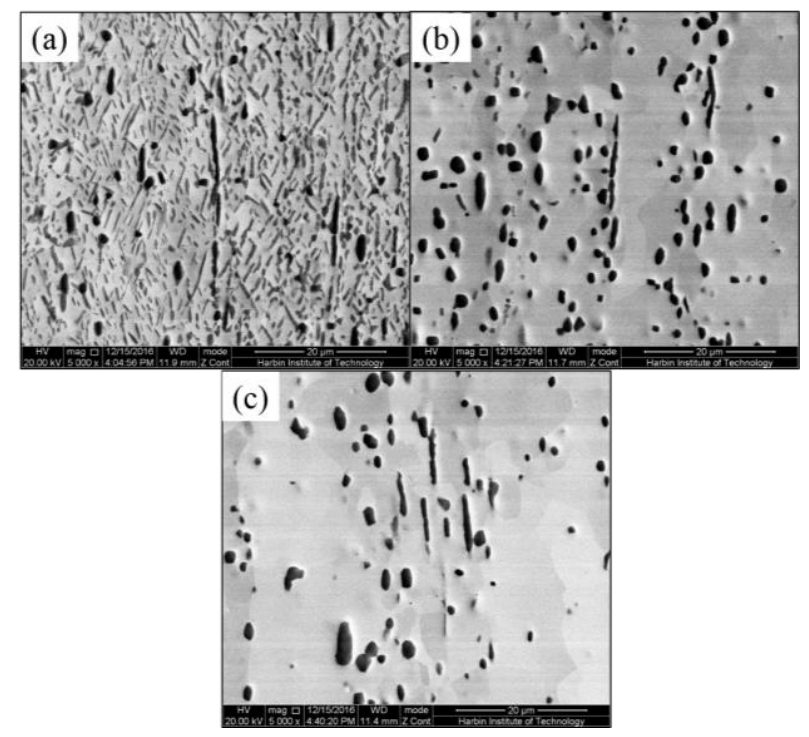

Fig. 7. Cross-section microstructure of the quadrate tubes formed at different temperatures, a) $950{ }^{\circ} \mathrm{C}$, b) $970{ }^{\circ} \mathrm{C}$, c) $990{ }^{\circ} \mathrm{C}$.

\subsection{Mechanical properties}

Fig. 8 shows the tensile properties at $750{ }^{\circ} \mathrm{C}$ for the $\mathrm{Ti}$ $22 \mathrm{Al}-24 \mathrm{Nb}-0.5 \mathrm{Mo}$ quadrate tubes. It is noted that the tensile strength increased but the elongation-to-failure decreased with the increasing of forming temperature. The tensile strength of quadrate tubes formed at $950{ }^{\circ} \mathrm{C}$, $970{ }^{\circ} \mathrm{C}$ and $990{ }^{\circ} \mathrm{C}$ was $793 \mathrm{MPa}, 906 \mathrm{MPa}$, and 921 $\mathrm{MPa}$, respectively. This trend also confirmed the damage results achieved in simulations, demonstrating that the microstructural damage is harmful to the strength. Due to the existing of $\mathrm{O}$ phase (Fig. 7a), the quadrate tube formed at $950{ }^{\circ} \mathrm{C}$ exhibited a high elongation-to-failure of $14.9 \%$. It has been reported that the $\mathrm{O}$ phase contributed to the improvement of ductility by dispersing operative dislocations [8].As the forming temperature increases, the elongation-to-failure decreases due to the reduced volume fraction of $\mathrm{O}$ phase. When the forming temperature increased to $990{ }^{\circ} \mathrm{C}$, the elongation-tofailure decreased to $2.8 \%$, indicating that the larger grain size of $\beta / \mathrm{B} 2$ phase was detrimental to the ductility.

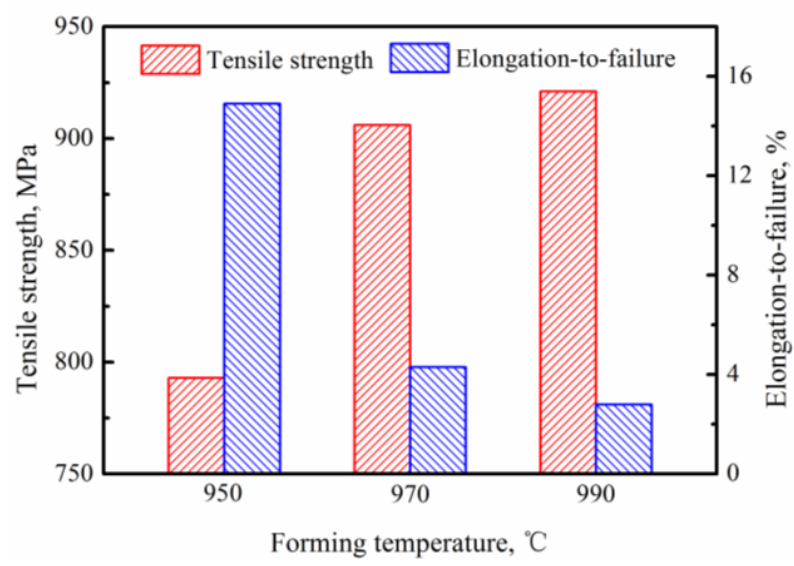

Fig. 8 Tensile properties at $750{ }^{\circ} \mathrm{C}$ for the Ti-22Al-24Nb0.5 Mo quadrate tubes.

\subsection{Precision of the component}

Table 1 lists the thickness thinning ratio along the crosssection of quadrate tubes formed at different temperatures. The point number is marked in white front, as shown in Fig. 6. Apparently, the maximum thickness thinning occurred in the transition region between straight region and round region, which also verified the thickness distribution achieved in simulation. Due to the friction on the straight region, the transition region primely satisfies plastic yielding condition and produces compressive strain through the thickness [9]. From the comparison of thickness thinning ratio for the quadrate tubes formed at different temperatures, it is noted that the biggest fluctuation of wall thickness appeared in the tube formed at $950{ }^{\circ} \mathrm{C}$ due to the significant strain softening. However, a relatively stable thinning ratio of $15 \%-19 \%$ was achieved in the quadrate tubes formed at $970{ }^{\circ} \mathrm{C}$ and $990{ }^{\circ} \mathrm{C}$. Based on the simulation results, the suggested forming temperature is $970{ }^{\circ} \mathrm{C}$, which is optimum to gain the qualified component at low energy consumption. 
Table 1. Thickness thinning ratio along the cross-section of quadrate tubes formed at different temperatures.

\begin{tabular}{|c|c|c|c|}
\hline \multirow{2}{*}{$\begin{array}{l}\text { Point } \\
\text { number }\end{array}$} & \multicolumn{3}{|c|}{ Thinning ratio $(\%)$ for tube formed at } \\
\hline & $950^{\circ} \mathrm{C}$ & $970^{\circ} \mathrm{C}$ & $990^{\circ} \mathrm{C}$ \\
\hline 1 & 16.37 & 16.58 & 15.75 \\
\hline 2 & 17.04 & 15.61 & 16.50 \\
\hline 3 & 18.54 & 16.68 & 16.95 \\
\hline 4 & 18.15 & 16.68 & 17.75 \\
\hline 5 & 20.00 & 17.46 & 18.50 \\
\hline 6 & 19.63 & 18.44 & 18.50 \\
\hline 7 & 16.22 & 17.95 & 18.50 \\
\hline 8 & 14.41 & 17.12 & 15.60 \\
\hline 9 & 13.43 & 16.10 & 16.15 \\
\hline 10 & 13.89 & 16.93 & 16.00 \\
\hline 11 & 13.50 & 16.98 & 15.25 \\
\hline 12 & 13.67 & 16.83 & 16.00 \\
\hline 13 & 16.41 & 16.68 & 17.50 \\
\hline 14 & 17.95 & 18.78 & 17.25 \\
\hline 15 & 18.86 & 18.15 & 17.05 \\
\hline 16 & 17.83 & 17.95 & 16.90 \\
\hline 17 & 17.10 & 16.83 & 15.40 \\
\hline 18 & 16.65 & 15.71 & 14.97 \\
\hline 19 & 16.63 & 15.85 & 15.20 \\
\hline
\end{tabular}

\section{Conclusions}

The finite element model of hot gas forming was established based on the unified viscoplastic constitutive model with coupling of microstructure and mechanical parameters. The microstructure evolution and shape fabricating for the hot gas forming of Ti-22Al-24Nb$0.5 \mathrm{Mo}$ quadrate tube was predicted by simulation. Besides, the corresponding hot gas forming of Ti-22Al$24 \mathrm{Nb}-0.5 \mathrm{Mo}$ quadrate tube was also conducted at 950$990{ }^{\circ} \mathrm{C}$. The results on wall thickness distribution, microstructure evolution and mechanical properties were summarized as follows:

(1) The unified viscoplastic constitutive equations can effectively predict the wall thickness distribution and microstructural evolution for the Ti-22Al-24Nb-0.5Mo quadrate tube. The forming temperature of $970{ }^{\circ} \mathrm{C}$ is suggested to gain the qualified component at low energy consumption.

(2) The maximum thinning occurred in the transition section of the quadrate tube due to the effect of friction. The biggest fluctuation of wall thickness appeared in the quadrate tube formed at $950{ }^{\circ} \mathrm{C}$ resulting from the significant strain softening. The forming temperature of $970{ }^{\circ} \mathrm{C}$ and $990{ }^{\circ} \mathrm{C}$ is suggested to achieve the uniform thickness for the Ti-22Al-24Nb-0.5Mo quadrate tubes.

(3) During the gas forming, the initial $O$ phase was coarsened at $950{ }^{\circ} \mathrm{C}$ and dissolved at $970{ }^{\circ} \mathrm{C}$. The tube formed at $950{ }^{\circ} \mathrm{C}$ exhibited high elongation-to-failure of $14.9 \%$ at $750{ }^{\circ} \mathrm{C}$ due to the existing of ductile $\mathrm{O}$ phase.
As the forming temperature increased to $970{ }^{\circ} \mathrm{C}$ and $990{ }^{\circ} \mathrm{C}$, the elongation-to-failure decreased to $4.3 \%$ and $2.8 \%$, and strength increased to $906 \mathrm{MPa}$ and $921 \mathrm{MPa}$, respectively.

This work was financially supported by National High-level Personnel of Special Support Program (No. W02020239).

\section{References}

1. D. Banerjee, A.K. Gogia, T.K. Nandy, V.A. Joshi, Acta Metall. 36, 871 (1988)

2. S.R. Dey, S. Roy, S. Suwas, J.J. Fundenberger, R.K. Ray, Intermetallics. 18, 1122 (2010)

3. J. Kumpfert, Adv. Eng. Mater. 3, 851 (2001)

4. C.J. Boehlert C.J., Mater. Sci. Eng., A. 267, 82 (1999)

5. G. Liu, Y. Wu, D. Wang, S. Yuan, Int. J. Adv. Manuf. Tech. 81, 1809 (2015)

6. K.Wang, G. Liu, J. Zhao, J. Wang, S. Yuan, Mater. Des, 91, 269 (2016)

7. Y. Wu, High temperature unified viscoplastic constitutive model and high pressure gas bulging of Ti-22Al-24.5Nb-0.5Mo sheet, Harbin Institute of Technology, 100 (2017)

8. Y. Wu, L. Zhen, D.Z. Yang, M.S. Kim, S.K. Hwang, Y. Umakoshi, Intermetallics, 12, 43 (2004)

9. G. Liu, S. Yuan, B. Teng, J. Mater. Process. Tech. 177, 688 (2006) 